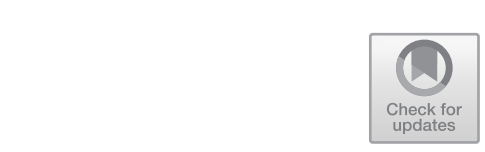

\title{
Conditio sine qua non
}

Notwendige Bedingung, ohne die etwas anderes nicht eintreten kann. Bedingung im medizinischnaturwissenschaftlichen Sinn. Grundlage der $\rightarrow$ Kausalität und jeder $\rightarrow$ Kausalitätstheorie.

\section{Curriculare Fortbildung}

Von der Bundesärztekammer im Jahr 2003 erarbeitete und im Jahre 2009 überarbeitete strukturierte Fortbildung (Curriculum "Grundlagen der medizinischen Begutachtung") zur Erlangung der führbaren Bezeichnung $\rightarrow$ „Medizinische Begutachtung“. Der dafür erforderliche Grundlagenkurs umfasst derzeit (Stand 16.11.2018) die Module I, II und III mit insgesamt 64 Stunden, die z. B. von den Landesärztekammern angeboten werden.

(C) Springer-Verlag GmbH Deutschland, ein Teil von Springer

Nature 2020

E. Ludolph, Arztliche Begutachtung von $A-Z$, https://doi.org/10.1007/978-3-662-61740-3_3 